\title{
A VIBGYYOR

\section{Potential of Manufacturing Low Cost MIM Stainless Steel Parts from Coarse Powders}

\author{
Youhua $\mathrm{Hu}^{1}$, Yimin $\mathrm{Li}^{2}$, Jia $\mathrm{Lou}^{3}$, Hao $\mathrm{He}^{2}$ and Liujun $\mathrm{Li}^{1}$
}

'State Key Laboratory of Powder Metallurgy, Central South University, China

${ }^{2}$ Research Centre for Materials Science and Engineering, Guangxi University of Science and Technology, China

${ }^{3}$ School of Materials Science and Engineering, Xiangtan University, China

\begin{abstract}
The aim of this study is to investigate the potential of producing low-cost metal injection molding (MIM) parts from irregular coarse powders. Water-atomized (WA) $316 \mathrm{~L}$ stainless steel (SS) powders with different particle sizes were used, including $-100,-200$, and -400 mesh powders. The flowability of their feedstocks, sintered microstructure, mechanical properties, and corrosion resistance of tested samples have been measured in this study. The results revealed that considerably good flowability can be achieved by feedstocks prepared from -200 and -400 mesh powders. The mechanical properties of MIM SS parts made from -200 mesh powders are equivalent or even superior to the MPIF standards. Similar corrosion resistance is obtained by parts made from -200 and -400 mesh powders, which also confirms that the -400 mesh powder is a promising low cost alternative for MIM SS applications.
\end{abstract}

\section{Keywords}

MIM, Stainless steel parts, Coarse powders, Mechanical properties, Corrosion resistance

\section{Introduction}

Recently, metal injection molding (MIM) has emerged and rapidly developed as a powder metallurgy net-shaping process. Increasing attention has been paid to this process as a promising technology to produce small parts with complex geometric shapes $[1,2]$. Although MIM process is a cost-effective technology to precisely fabricate large quantities of small and intricate parts, researchers and manufacturers are highly concerned with the costly raw materials used in the process [3]. Such costly applications of MIM involve fine $(<10-20 \mu \mathrm{m})$ powders with spherical particle shape that are typically manufactured by gas atomization (GA) process. However, the cost of applying MIM to stainless steel (SS) powder with irregularly shaped particles using water atomization (WA) process is only one fifth of that produced by GA process [4,5]. Applying MIM to coarse powders is key to reduce the costs of raw materials.

In addition to their low cost, coarse powders can provide other advantages compared to fine powders. A bimodal or trimodal powder feedstock can effectively improve the powder loading [6]. Furthermore, coarse powder contributes to the success of injection molding of relatively large parts [7]. The use of coarse powders can also enhance the debinding process. Fine and spherical powders produce small inter-particle pores that hinder the solvent and thermal debinding, which increases the total processing cycle time [8].

Although the benefits of coarse powder feedstock are widely recognized, their use is limited because they exhibit poor flowability and sintering behavior. As reported in our previous study, the parts manufactured by WA

*Corresponding author: Yimin Li, Research Centre for Materials Science and Engineering, Guangxi University of Science and Technology, 545006, China

Accepted: August 13, 2018: Published: August 15, 2018

Copyright: @ $2018 \mathrm{Hu} \mathrm{Y,} \mathrm{et} \mathrm{al.} \mathrm{This} \mathrm{is} \mathrm{an} \mathrm{open-access} \mathrm{article} \mathrm{distributed} \mathrm{under} \mathrm{the} \mathrm{terms} \mathrm{of} \mathrm{the} \mathrm{Creative} \mathrm{Commons} \mathrm{Attribution}$ License, which permits unrestricted use, distribution, and reproduction in any medium, provided the original author and source are credited. 


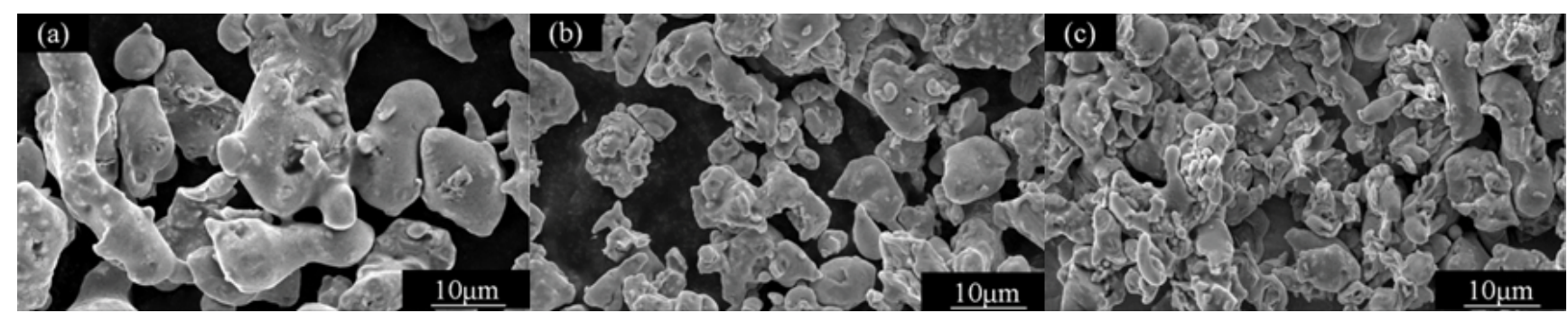

Figure 1: Morphologies of SS powders: a) -100 mesh; b) -200 mesh; and c) -400 mesh.

Table 1: Particle size distribution of SS powders.

\begin{tabular}{|l|l|l|l|}
\hline Powder & $\mathbf{D}_{10}(\boldsymbol{\mu m})$ & $\mathbf{D}_{\mathbf{5 0}}(\boldsymbol{\mu m})$ & $\mathbf{D}_{\mathbf{9 0}}(\boldsymbol{\mu m})$ \\
\hline-100 mesh WA SS & 22.3 & 65.71 & 160.96 \\
\hline-200 mesh WA SS & 8.51 & 26.69 & 63.47 \\
\hline-400 mesh WA SS & 7.21 & 19.25 & 40.34 \\
\hline
\end{tabular}

Table 2: Chemical composition of SS powder.

\begin{tabular}{|l|l|l|l|l|l|l|l|l|l|}
\hline $\mathbf{C r}$ & $\mathbf{N i}$ & Mo & $\mathbf{M n} \mathbf{S i}$ & $\mathbf{C}$ & $\mathbf{P}$ & $\mathbf{S}$ & $\mathbf{O}$ & $\mathbf{F e}$ \\
\hline $16 \sim 18$ & $12 \sim 15$ & $2 \sim 3$ & 0.2 & 0.8 & $\leq 0.03$ & $\leq 0.03$ & $\leq 0.02$ & $\leq 0.3$ & Bal. \\
\hline
\end{tabular}

powders were sintered to a maximum of only $93 \%$ density, which is much lower than the $97 \%$ achieved by GA process; the strength and hardness of components produced using WA are inferior compared to those obtained by GA process with comparable ductility and corrosion resistance [9]. Another study also confirmed the superior properties of parts fabricated using coarse powder, which can match the properties of those fabricated using MIM applied to fine powder or even wrought materials [3].

In this study, feedstocks prepared form WA SS powders with coarse and irregular shaped powder are tested to examine their flowability and debinding behavior and determine the appropriate particle size to reduce the production cost. The sintered density, mechanical properties, and corrosion resistance are also investigated. Based on the results of this study, a MIM oxidation process is described; such information could provide a theoretical basis for large-scale production of low cost SS parts.

\section{Experimental Procedures}

The tested WA 316L SS powders were provided by Handan ASL Atomized Powder Co., Ltd (China). The particle size distribution and morphologies of $-100,-200$, -400 mesh powders used in this study are shown in Table 1 and Figure 1, respectively. The chemical constituents of the tested powder are listed in Table 2.

Wax-based binder was selected in this study. Prior to injection, compositions are mixed in an XSM1/20-80 rubber mixer at a temperature of $160{ }^{\circ} \mathrm{C}$ for $180 \mathrm{~min}$ to prepare feedstocks. After granulation in an YHL04 plastic extruder, Archimedes spiral sample injection was performed using feedstocks with different powder loading to investigate the flowability of feedstocks under differ-

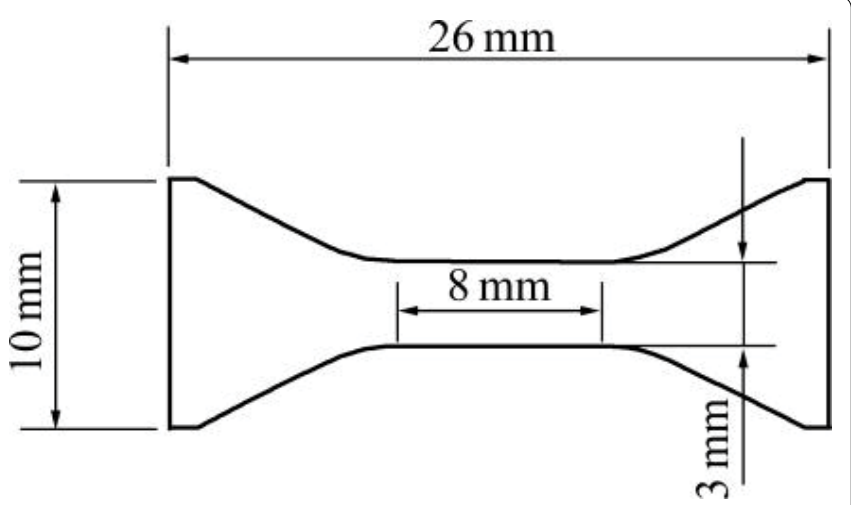

Figure 2: Sketch of the tensile specimen.

ent injection molding conditions. Then the parts used for debinding testing were molded on a molding machine. The parameters of tested parts are listed in Table 3. Standard tensile parts were molded using a BOY50T2 molding machine. The tensile specimen for tensile and corrosion test is shown in Figure 2. The detailed dimensions are listed in Table 3.

The solvent debinding was performed by immersion of compacts in methylene chloride at $40^{\circ} \mathrm{C}$ for $120 \mathrm{~min}$. Then, thermal debinding was carried out under argon atmosphere with a flux of $5 \mathrm{Lmin}^{-1}$. Sintering was performed at $1350{ }^{\circ} \mathrm{C}, 1360{ }^{\circ} \mathrm{C}$, or $1375{ }^{\circ} \mathrm{C}$ for $2 \mathrm{~h}$ under argon atmosphere.

The weight loss ratio of parts was measured. The tensile test was performed using a Instron testing machine. A Polyvar-met metallographic microscope was used to examine the microstructure of tested parts, and a KYKY2800 scanning electronic microscope was used to observe fractography.

Testing for debinding ratio, sintered density, tensile properties and corrosion resistance were repeated 3 times at least. Weight loss immersion test was performed using $5 \%$ hydrochloric acid solution, which was kept in water bathing at $50{ }^{\circ} \mathrm{C}$ to determine the corrosion resistance of selected sintered samples with satisfactory properties. The tested samples were immersed in hydrochloric acid solution for $72 \mathrm{~h}$. The samples were taken out 6 times to measure their corrosion rate, which can be calculated by the following equation [10]: 
Table 3: Parameters of parts used for debinding testing.

\begin{tabular}{|l|l|l|l|l|}
\hline Sample & Thickness $\mathbf{( m m})$ & Weight $\mathbf{( g )}$ & Molding pressure $\mathbf{( M P a )}$ & Density of $\mathbf{p a r t s}\left(\mathbf{g} \cdot \mathbf{c m}^{\mathbf{- 3}}\right)$ \\
\hline 1 & 10 & 38.4 & & \\
\hline 2 & 15 & 57.6 & 10 & 4.81 \\
\hline 4 & 20 & 76.8 & & \\
\hline
\end{tabular}

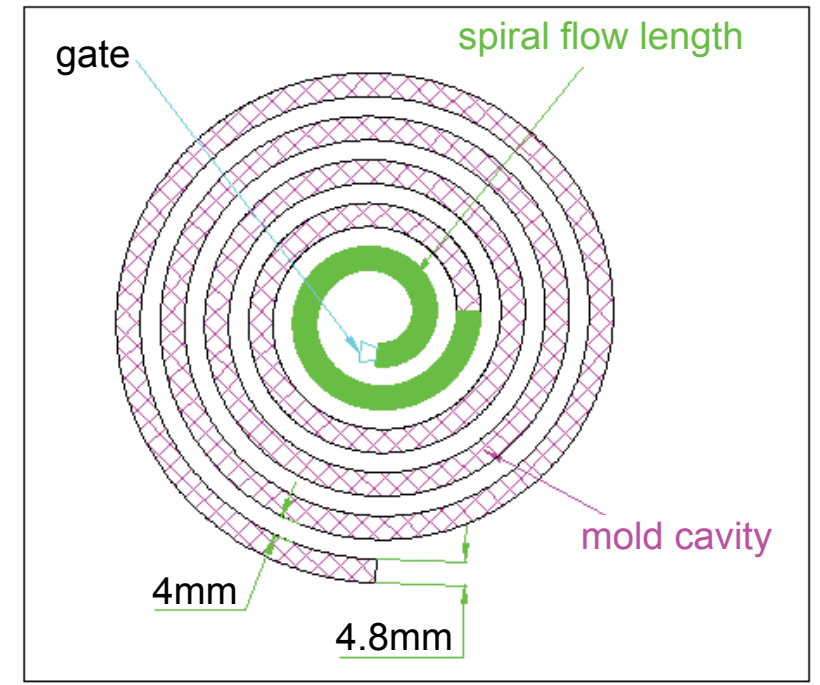

$3 \mathrm{~mm}$

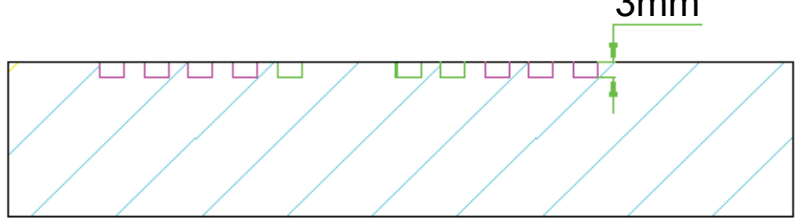

Figure 3: Sketch of the Archimedes spiral mold.

$$
R=\frac{W}{A \cdot T}
$$

where $R$ is the corrosion rate, $W$ the weight loss (g), $A$ the sample area $\left(\mathrm{m}^{2}\right)$, and $t$ is the corrosion time (h).

\section{Results and Discussion}

\section{Flowability}

The spiral flow length (SFL) of feedstocks is an important parameter to determine their flowability. The Archimedes spiral mold is shown in Figure 3, the spiral flow length of the feedstocks was taken as the criterion of the fluidity.

The effects of different injection parameters on SFL, such as the mold temperature, injection pressure and injection velocity, are shown in Figure 4. Measuring the SFL of feedstock prepared from - 100 mesh powder is difficult owing to its low flowability. Figure 4 shows that the feedstock prepared from -200 mesh powder exhibits better flowability than that prepared from -400 mesh powder. Thus, it can be concluded that using a proper volume of coarse powder can promote flowability. Owing to its irregular particle shape, the feedstock prepared using WA powder exhibit inferior flowability compared
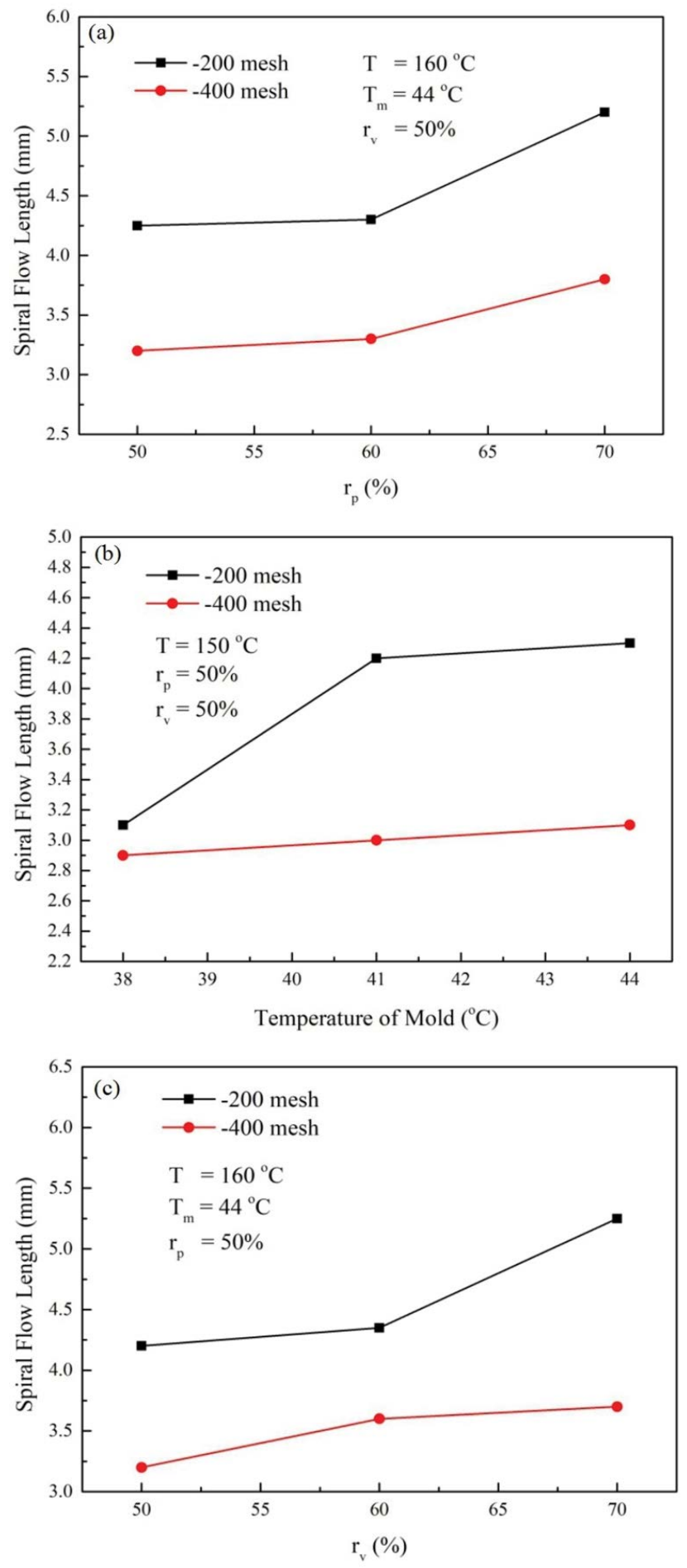

Figure 4: Influence of injection parameters on SFL: a) $T_{m}{ }^{-}$ mold temperature; b) $r_{p}$-ratio of actual injection pressure to total injection pressure; and c) $r_{v}$-ratio of actual injection velocity to total injection velocity.

to those reported for GA powders. However, better flow- 
ability can be achieved by applying higher mold temperature, injection temperature, pressure, and speed. The higher mold temperature and injection temperature lead to slower front cooling and better fluidity of feedstocks, respectively. The faster injection speed has shortened the filling time of feedstock.

\section{Debinding}

Green compacts with high thickness were prepared to investigate the debinding behavior of samples. Preparing compacts from -100 mesh is very difficult because of their inferior flowability. The effects of sample thickness on the debinding behavior of green compacts prepared from -200 mesh and -400 mesh powders are shown in Figure 5. Faster debinding rate was detected in compacts prepared from -200 mesh powder than those prepared from -400 mesh powder, especially when the sample thickness ranged between $10 \mathrm{~mm}$ and $15 \mathrm{~mm}$.

Different debinding mechanism should be used to explain this phenomenon. The debinding rate is controlled by two mechanisms: Liquid diffusion and vapor transportation. During debinding, the low molecular binder evaporates, dissolves into the melt, and then diffuses to

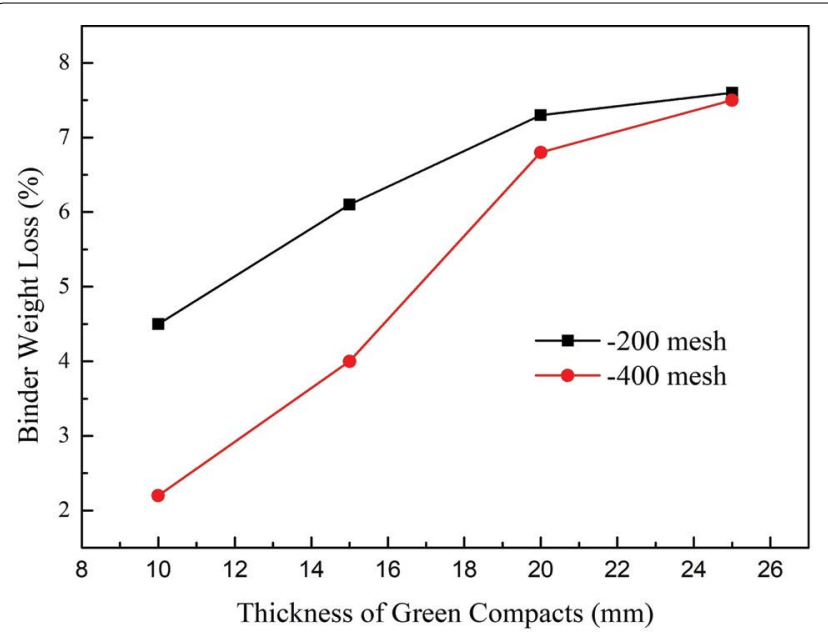

Figure 5: Effects of sample thickness on debinding behavior of green compacts prepared from -200 mesh and -400 mesh (at $500{ }^{\circ} \mathrm{C}$ for $30 \mathrm{~min}$ ). the binder-atmosphere interface. Next, the evaporated binder transports through the interconnected pore channels to the outer atmosphere. If the sample is not sufficiently thick, the debinding rate is controlled by the liquid diffusion; thus, the sample thickness has negligible influence on the debinding rate. If the sample thickness is above the critical compact thickness $\left(H_{C}\right)$, the kinetic controlling step during debinding transforms from liquid diffusion control to vapor transportation control [11]. The debinding rate is controlled by the factors affecting the vapor transportation, such as the volume of interconnected pore channels, diameter of pores, and length of channels, i.e. the thickness of green compacts.

The thickness of compact should be larger than $H_{C}$; thus, the debinding dynamics during the formation of open pores are controlled by the liquid diffusion. If the sample has a large critical thickness, the debinding is accelerated in the initial stage of the process, and debinding defects or distortion are less likely to occur in brown compacts. The debinding critical thickness can be calculated using equation (2), as follow [11]:

$$
H_{C}=\frac{\tau L \rho E^{4} d^{2}\left(P^{2}-P_{0}^{2}\right)}{D_{0} E X P(-Q / R T) \cdot \Delta C(1-\Phi) \cdot\left[90-(1-\mathrm{E})^{2}\right] \cdot 2 \mathrm{GP}}
$$

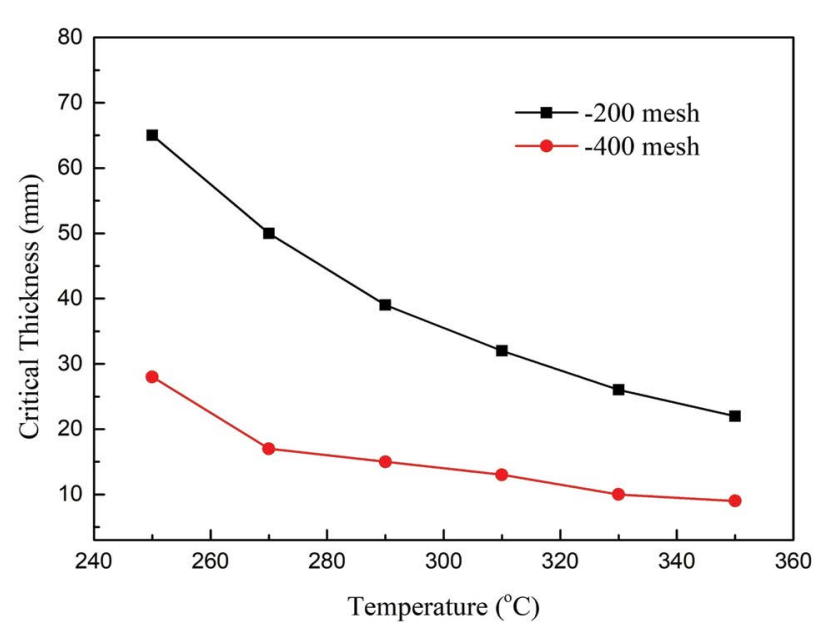

Figure 6: Influence of powder particle size on critical thickness.

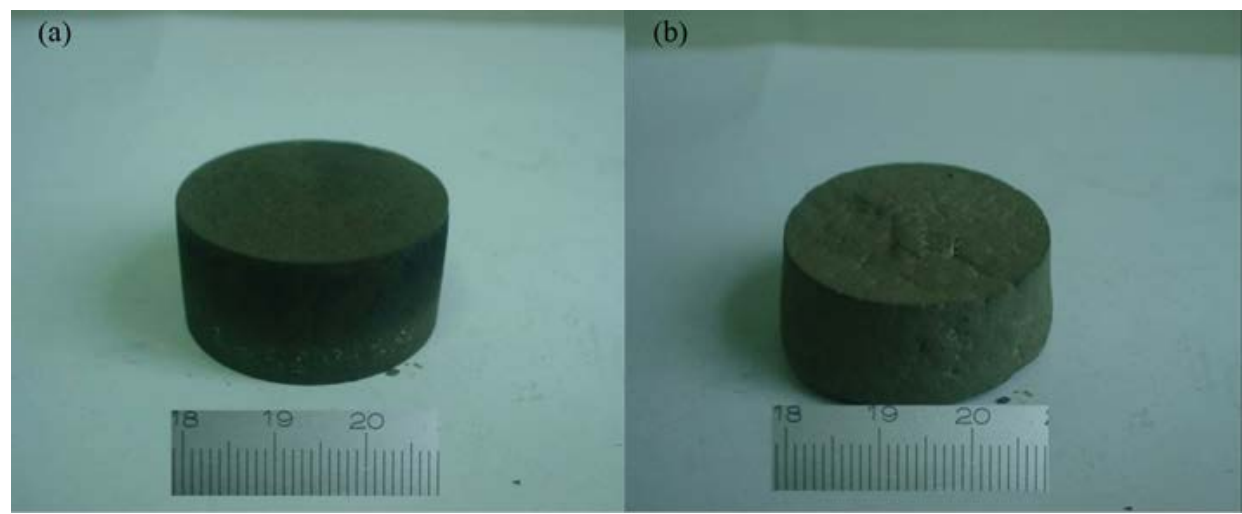

Figure 7: Images of $15 \mathrm{~mm}$ thick brown compacts prepared using: a) -200 mesh powder and b) -400 mesh powders. 
where $R$ is the gas constant, $T$ is the absolute temperature, $\Delta C$ is the concentration gradient, $\Phi$ is the powder loading, $G$ is the vapor viscosity, $P$ is the gas pressure at the binder-vapor interface, $P_{0}$ is the external gas pressure on the compact surface, $\tau$ is the tortuosity, $d$ is the powder diameter, $L$ is the diffusion distance, and $\rho$ is the density of evaporated or decomposed vapor of binder.

Theoretical calculation is carried out on feedstocks prepared from -200 and -400 mesh powders with powder loading of $55 \%$. The calculated critical thicknesses are shown in Figure 6, which have covered the majority of debinding temperature ranges. It can be seen that the critical thickness of -200 mesh powder is approximately twice as thick as that of - 400 mesh powder at any debinding temperature. Hence, the debinding process can be accelerated, and less residual binder is achieved for compacts made by coarse powder at the same temperature, which can decrease the debinding cost.

In addition to accelerating the debinding process, the preparation of brown compact can reflect the debinding behavior. Images of $15 \mathrm{~mm}$ thick brown compacts are shown in Figure 7. The compact prepared from -200 mesh powder has a good surface finish with no visible defects; its weight loss ratio is approximately $6.12 \%$. Al-

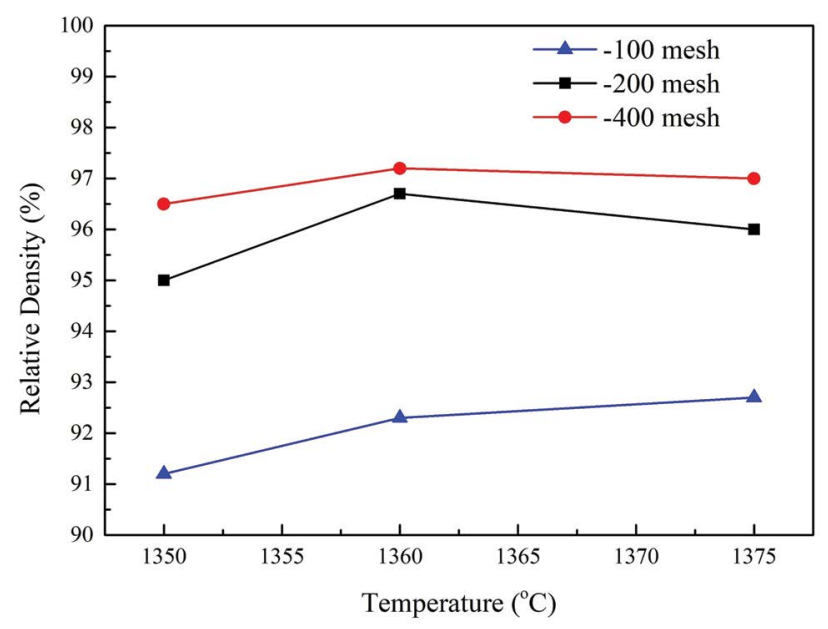

Figure 8: Relative density of WA SS samples sintered at different temperatures. though the compact prepared from -400 mesh powder has lower weight loss ratio of approximately $4.09 \%$, visible distortion and bubbles can be seen on its surface. Hence, the green compacts prepared from coarse powder exhibit superior debinding properties, which is beneficial to produce large MIM parts.

\section{Mechanical properties and microstructure}

The relative density of sintered WA SS samples prepared from different powders is shown in Figure 8. The finer the particle size, the higher the density. Samples prepared from -200 and -400 mesh powders can achieve a relative density of approximately $97 \%$ at $1360^{\circ} \mathrm{C}$; applying higher temperature $\left(1375^{\circ} \mathrm{C}\right)$ leads to over-sintering, which decreases the density. However, the relative density of samples prepared from -100 mesh powder was less than $93 \%$, even though the sintering temperature reached $1375^{\circ} \mathrm{C}$. The microstructures of tested samples are shown in Figure 9. The sample shown in Figure 9a exhibits inferior mechanical properties; many large sized interconnected pores can be detected, and the average grain size is approximately $90 \mu \mathrm{m}$. Figure $9 \mathrm{~b}$ and Figure $9 \mathrm{c}$ show samples with almost equivalent grains and pore sizes; their grain size is approximately $65 \mu \mathrm{m}$ and $40 \mu \mathrm{m}$, respectively.

The mechanical properties of sintered WA SS samples prepared from different powders are shown in Figure 10. The finer the particle size, the better the mechanical properties, which correspondence to the sample density. The sample prepared from - 100 mesh powder has inferior properties, while those prepared from -200 and -400 mesh exhibit very good mechanical properties when sintered at $1360^{\circ} \mathrm{C}$, as they all exceed the MPIF standard levels for sintered SS parts (520 MPa tensile strength and $50 \%$ elongation [12].

The fracture surfaces of sintered samples prepared from different powders are shown in Figure 11. As a proxy of ductility, dimple is the micro void produced by plastic deformation of material in the range of microzone. Large number of pores with very big dimple can be seen in the samples prepared from - 100 mesh powder,

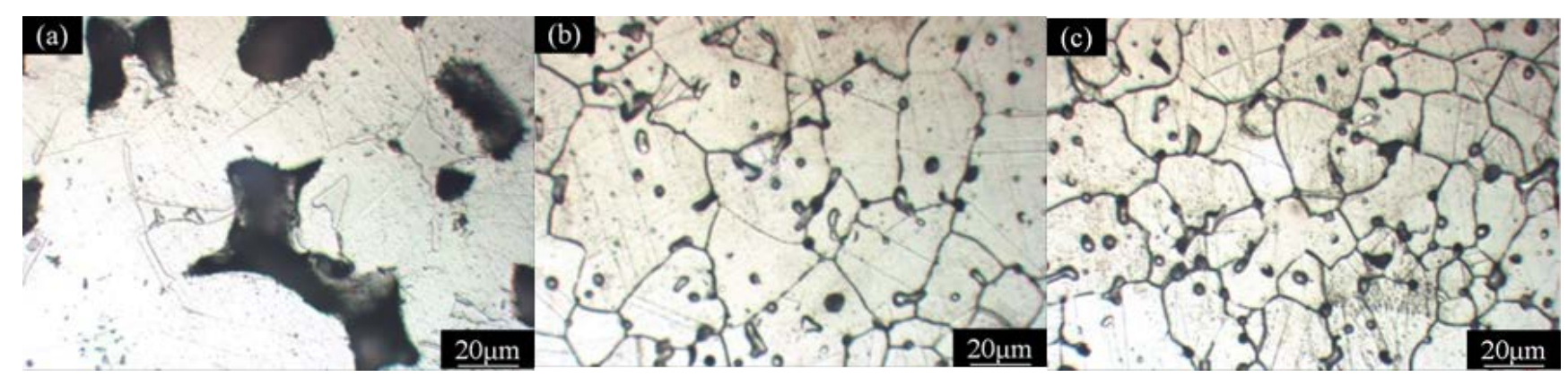

Figure 9: Microstructure of WA SS samples sintered at $1360{ }^{\circ} \mathrm{C}$ using a) -100 mesh powder; b) -200 mesh powder; and c) -400 mesh powder. 
as shown in Figure 11a, which indicates that big porosity leads to an inferior ductility. On the other hand, Figure $11 \mathrm{~b}$ and Figure 11c show large amounts of dimples, large pore is absent. This indicates that the samples have suffered significant plastic deformation. The WA powder achieved better elongation results than that obtained by the GA SS samples (42\%) [9].

\section{Corrosion resistance}

The corrosion rates of samples prepared from -100 , -200 , and -400 mesh powders are shown in Figure 12.
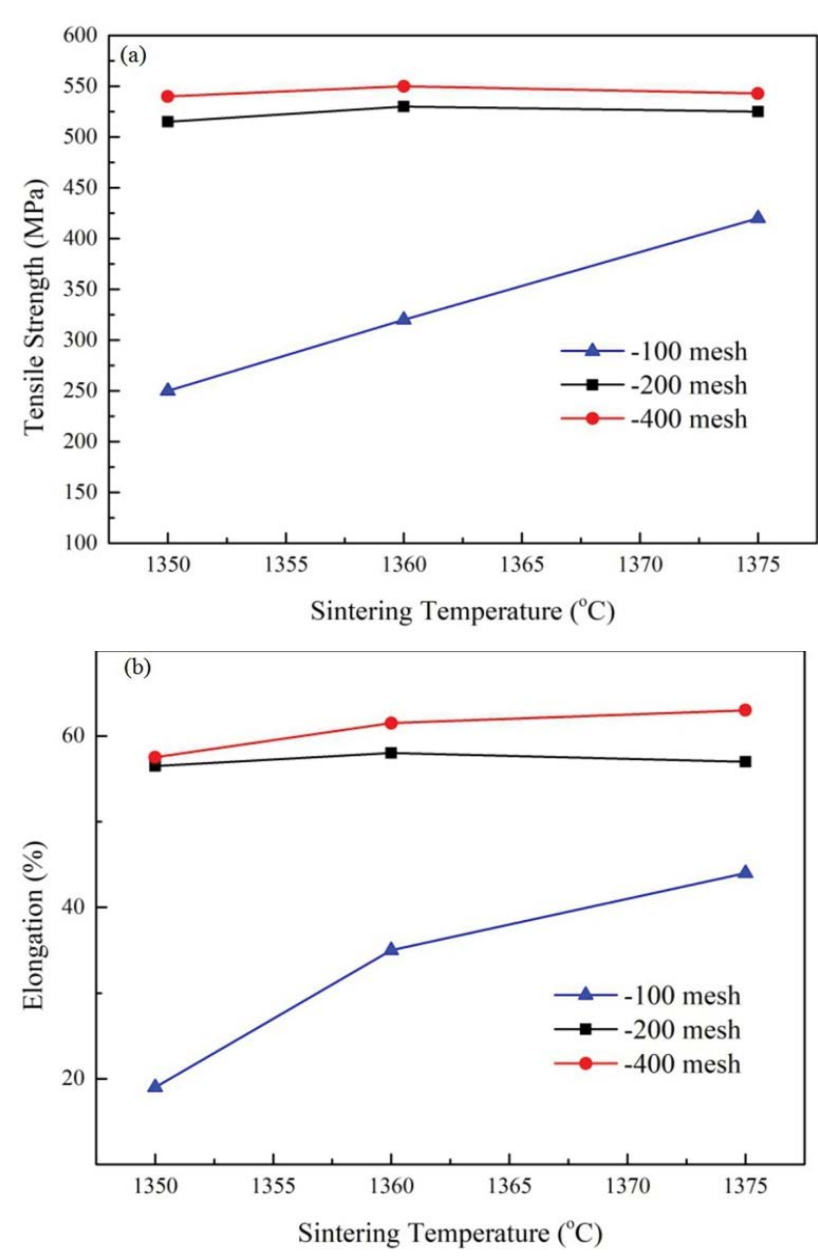

Figure 10: Mechanical properties of WA SS samples sintered at different temperatures: a) Tensile strength and b) Elongation.
The sample prepared from -100 mesh powder exhibits very poor corrosion resistance, although it was sintered at $1375{ }^{\circ} \mathrm{C}$ to achieve higher density, whereas the samples prepared from -200 and -400 mesh powders were sintered at $1360{ }^{\circ} \mathrm{C}$. Furthermore, the corrosion rate significantly accelerates after $36 \mathrm{~h}$. In the meantime, the samples prepared from -200 and -400 mesh powders show considerably good and almost equivalent corrosion resistance. The corrosion resistance is primarily influenced by the presence of residual pores in the samples. As shown in Figure 9, the samples prepared from -200 and -400 mesh powders show fine spherical pores, compared to the presence of large interconnected pores in the sample prepared from - 100 mesh powder. It is worth noting that the sample prepared using WA powder exhibits better corrosion resistance than that prepared using GA powder. This can be attributed to the fact that the $\mathrm{SiO}_{2}$ precipitates in the WA sample greatly favors the passivation effect of stainless, which was discussed in a previous study [9].

\section{Conclusion}

1) The results demonstrate that feedstocks prepared from -200 and -400 mesh WA SS coarse powders have moderate flowability.

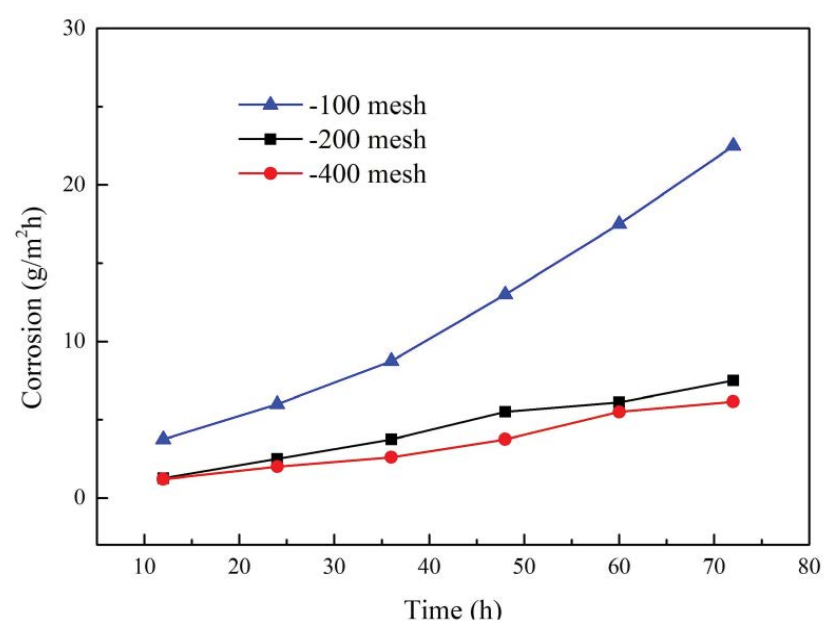

Figure 12: Corrosion rate of parts prepared from different powder.

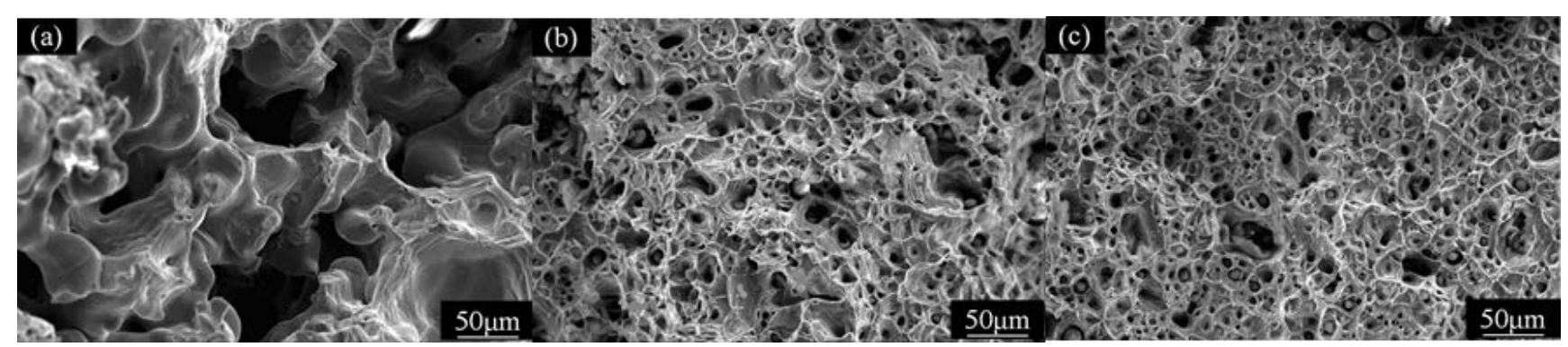

Figure 11: Fracture surfaces of sintered samples prepared from: a) -100 mesh powder; b) -200 mesh powder; and c) -400 mesh powder. 
2) Faster debinding rate is achieved by green compacts prepared from -200 mesh powder compared to those prepared from -400 mesh powder. Defects and distortion are less likely to occur in the former. Hence, using coarse powder enhances the debinding process.

3) Sintered compacts prepared from -200 and -400 mesh powders exhibit satisfactory density and mechanical properties, which exceed the MPIF standard levels for sintered SS parts, whereas sintered compacts prepared from -100 mesh powder show inferior properties.

4) Sintered compacts prepared from -200 and -400 mesh powders have excellent corrosion resistance. The pore structure and silicon oxides formed in the SS is accounted for the corrosion behavior of samples prepared from WA SS coarse powders.

\section{Acknowledgement}

The authors acknowledge support from the Hunan Provincial Natural Science Foundation (Grant No. 2018JJ3507), the Guangxi Science and Technology Plan Project (Grant No. AD16380019), and the China Postdoctoral Science Foundation (Grant No. 2018M632978).

\section{References}

1. J Lou, Y Li, H He, D Li, G Wang, et al. (2017) Interface development and numerical simulation of powder co-injection moulding. Part. I. Experimental results on the flow behaviour and die filling process. Powder Technology 305: 405-410.

2. J Lou, Y Li, H He, D Li, G Wang, et al. (2017) Interface development and numerical simulation of powder co-injection moulding. Part II. Numerical simulation and experimental verification. Powder Technology 305: 357-363.
3. B Qiao, F Shang, M Ding, HQ Li, YQ He, et al. (2010) Process of $316 \mathrm{~L}$ stainless steel coarse powder by injection molding. Journal of Aeronautical Materials 30: 30-35.

4. RP Koseski, P Suri, NB Earhardt, RM German, YS Kwon (2005) Microstructural evolution of injection molded gasand water-atomized $316 \mathrm{~L}$ stainless steel powder during sintering. Materials Science and Engineering A 390: 171-177.

5. H He, J Lou, Y Li, H Zhang, S Yuan, et al. (2018) Effects of oxygen contents on sintering mechanism and sintering-neck growth behaviour of $\mathrm{Fe}-\mathrm{Cr}$ powder. Powder Technology 329: 12-18.

6. JP Choi, JS Park, JI Song, WS Lee, JS Lee (2017) Design of trimodal Fe micro-nanopowder feedstock for micro powder injection molding. Powder Technology 317: 1-5.

7. R Hashikawa, T Osada, K Kudo, F Tsumori, H Miura (2016) Control the Distortion of the large and complex shaped parts by the metal injection molding process. Journal of the Japan Society of Powder and Powder Metallurgy 63: 473478.

8. KS Hwang, GJ Shu, HJ Lee (2005) Solvent debinding behavior of powder injection molded components prepared from powders with different particle sizes. Metallurgical and Materials Transactions A 36: 161-167.

9. J Lou, YM Li, H He, LJ Li (2010) Effect of atomization medium on sintering properties of austenitic stainless steel by eliminating influence of particle shape and particle size. Powder Metallurgy 53: 112-117.

10. E Cor (2004) Standard Practice for Laboratory Immersion Corrosion Testing of Metals 1. Corrosion 72: 1-8.

11. Y Li, F Jiang, L Zhao, B Huang (2003) Critical thickness in binder removal process for injection molded compacts. Materials Science and Engineering A 362: 292-299.

12. (1997) Materials Standards for Metal Injection molded Parts. Metal Powder Industries Federation, Princeton, NJ. 